\title{
ON THE SECOND DUAL SPACE OF THE BANACH SPACE OF VECTOR-VALUED LITTLE LIPSCHITZ FUNCTIONS
}

\author{
Shinnosuke IZUMI \\ (Received 24 September 2020 and revised 21 January 2021)
}

\begin{abstract}
Let $X$ be a compact metric space and $E$ be a Banach space. Then lip $(X, E)$ denotes the Banach space of all $E$-valued little Lipschitz functions on $X$. We show that $\operatorname{lip}(X, E)^{* *}$ is isometrically isomorphic to the Banach space of $E^{* *}$-valued $\operatorname{Lipschitz}$ functions $\operatorname{Lip}\left(X, E^{* *}\right)$ under several conditions. Moreover, we describe the isometric isomorphism from $\operatorname{lip}(X, E)^{* *}$ to $\operatorname{Lip}\left(X, E^{* *}\right)$.
\end{abstract}

\section{Introduction}

Let $X$ be a compact metric space with metric $d, \mathbb{K}$ be a field of real numbers or complex numbers, $E$ be a Banach space over $\mathbb{K}$ with norm $\|\cdot\|_{E}$ and $0<\alpha \leq 1$. Then $C(X, E)$ denotes the Banach space of all $E$-valued continuous functions on $X$ with norm

$$
\|f\|_{C(X, E)}:=\sup _{x \in X}\|f(x)\|_{E} .
$$

If $f \in C(X, E)$ satisfies the condition

$$
\mathcal{L}_{X, E}(f):=\sup _{\substack{x, x^{\prime} \in X \\ x \neq x^{\prime}}} \frac{\left\|f(x)-f\left(x^{\prime}\right)\right\|_{E}}{d\left(x, x^{\prime}\right)^{\alpha}}<\infty,
$$

then we say that $f$ is $\alpha$-Lipschitz. In particular, if $\alpha=1$, then we say that $f$ is Lipschitz. Then $\operatorname{Lip}_{\alpha}(X, E)$ denotes the set of all $E$-valued $\alpha$-Lipschitz functions on $X$. If $f \in \operatorname{Lip}_{\alpha}(X, E)$ satisfies the condition

$$
\lim _{d\left(x, x^{\prime}\right)^{\alpha} \rightarrow 0} \frac{\left\|f(x)-f\left(x^{\prime}\right)\right\|_{E}}{d\left(x, x^{\prime}\right)^{\alpha}}=0,
$$

then we say that $f$ is little $\alpha$-Lipschitz. In particular, if $\alpha=1$, then we say that $f$ is little Lipschitz. Then $\operatorname{lip}_{\alpha}(X, E)$ denotes the set of all $E$-valued little $\alpha$-Lipschitz functions on $X$. In the case that $E=\mathbb{K}$, we simply write $\operatorname{Lip}_{\alpha}(X):=\operatorname{Lip}_{\alpha}(X, \mathbb{K})$ and $\operatorname{lip}_{\alpha}(X):=$ $\operatorname{lip}_{\alpha}(X, \mathbb{K})$, respectively. In the case that $\alpha=1$, we simply write $\operatorname{Lip}(X, E):=\operatorname{Lip}_{1}(X, E)$ and $\operatorname{lip}(X, E):=\operatorname{lip}_{1}(X, E)$, respectively.

2010 Mathematics Subject Classification: Primary 46B10; Secondary 46E40.

Keywords: little Lipschitz function; second dual space; Lipschitz function. 
Clearly, $\operatorname{Lip}_{\alpha}(X, E)$ is a Banach space over $\mathbb{K}$ with respect to the norm

$$
\|f\|_{\max }:=\max \left\{\|f\|_{C(X, E)}, \mathcal{L}_{X, E}(f)\right\} \quad(f \in \operatorname{Lip}(X, E)),
$$

and $\operatorname{lip}_{\alpha}(X, E)$ is a closed subspace of $\operatorname{Lip}_{\alpha}(X, E)$. Moreover, if $0<\alpha<1$, then $\operatorname{Lip}(X, E) \subset \operatorname{lip}_{\alpha}(X, E)$.

For any Banach space $B, B^{*}$ and $B^{* *}$ denote the dual space and second dual space of $B$, respectively. Also, $b^{*}$ and $b^{* *}$ denote the elements of $B^{*}$ and $B^{* *}$, respectively.

Weaver defined in [9] the following property to get a Stone-Weierstrass type theorem.

Definition 1. (Weaver [9]) Let $X$ be a compact metric space with metric $d$. We say that lip $(X)$ separates points uniformly if there exists a constant $c>1$ such that, for any $x, x^{\prime} \in X$ with $x \neq x^{\prime}$, some $f \in \operatorname{lip}(X)$ satisfies $\mathcal{L}_{X, \mathbb{K}}(f) \leq c$ and $\left|f(x)-f\left(x^{\prime}\right)\right|=d\left(x, x^{\prime}\right)$.

Bade, Curtis and Dales showed in [1] that $\operatorname{lip}_{\alpha}(X)$ separates points uniformly for $0<\alpha<1$.

Hanin [3] and Weaver [9] showed the following theorem.

Theorem A. (Hanin [3] and Weaver [9]) Let X be a compact metric space. The following are equivalent:

(a) $\operatorname{lip}(X)$ separates points uniformly;

(b) there exists $b>1$ such that, for any $g \in \operatorname{Lip}(X)$ and any finite subset $S \subset X$, some $f \in \operatorname{lip}(X)$ satisfies $\mathcal{L}_{X, \mathbb{K}}(f) \leq b \mathcal{L}_{X, \mathbb{K}}(g)$ and $f(x)=g(x)$ for $x \in S$;

(c) $\operatorname{lip}(X)^{* *}$ is isometrically isomorphic to $\operatorname{Lip}(X)$, via the mapping $\Lambda$ : $\operatorname{lip}(X)^{* *} \rightarrow$ $\operatorname{Lip}(X)$ defined by

$$
\left(\Lambda f^{* *}\right)(x)=f^{* *}\left(\tau_{x}\right) \quad\left(f^{* *} \in \operatorname{lip}(X)^{* *}, x \in X\right),
$$

where $\tau_{x}$ is the evaluation functional at $x$.

Also, Johnson [4, Theorem 4.7] and Bade, Curtis and Dales [1, Theorem 3.5] showed that $\operatorname{lip}_{\alpha}(X)^{* *}$ is isometrically isomorphic to $\operatorname{Lip}_{\alpha}(X)$.

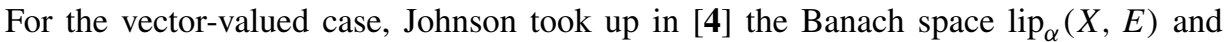
proved the following theorem.

THEOREM B. (Johnson [4]) Let $X$ be a compact metric space with metric $d$, E be a Banach space and $0<\alpha<1$. If either $E^{*}$ or $\operatorname{lip}_{\alpha}(X)^{*}$ has the approximation property, then $\operatorname{lip}_{\alpha}(X, E)^{* *}$ is isometrically isomorphic to $\operatorname{Lip}_{\alpha}\left(X, E^{* *}\right)$.

In this paper, we take up the Banach space $\operatorname{lip}(X, E)$ and get the following result.

THEOREM 1. Let $E$ be a Banach space and $X$ be a compact metric space with metric $d$. If $\operatorname{lip}(X)$ separates points uniformly and either $E^{*}$ or $\operatorname{lip}(X)^{*}$ has the approximation property, then $\operatorname{lip}(X, E)^{* *}$ is isometrically isomorphic to $\operatorname{Lip}\left(X, E^{* *}\right)$. Moreover, if $Q$ is an isometric isomorphism from $\operatorname{lip}(X, E)^{* *}$ to $\operatorname{Lip}\left(X, E^{* *}\right)$, then $Q$ is of the form

$$
\left(\left(Q f^{* *}\right)(x)\right)\left(e^{*}\right)=f^{* *}\left(e^{*} \otimes \tau_{x}\right)
$$

for any $f^{* *} \in \operatorname{lip}(X, E)^{* *}, x \in X$ and $e^{*} \in E^{*}$. 


\section{Preliminaries}

Throughout this section, we assume that $X$ is a compact metric space and $E$ is a Banach space with norm $\|\cdot\|_{E}$.

Proposition 2.1. Let $e^{*} \in E^{*}$ and $f \in \operatorname{lip}(X, E)$. A function $e^{*} \circ f: X \rightarrow \mathbb{K}$ defined by

$$
\left(e^{*} \circ f\right)(x)=e^{*}(f(x)) \quad(x \in X)
$$

satisfies $e^{*} \circ f \in \operatorname{lip}(X)$ and $\left\|e^{*} \circ f\right\|_{\max } \leq\left\|e^{*}\right\|_{E^{*}}\|f\|_{\max }$.

Proof. Straightforward.

The next proposition implies that $\operatorname{lip}(X)^{*}$ has the Radon-Nikodým property (see e.g. [7, Corollary 5.42]).

Proposition 2.2. If $\operatorname{lip}(X)$ separates points uniformly, then $\operatorname{lip}(X)^{*}$ is separable.

Proof. By noting that $X$ is a compact metric space, there exists a countable dense subset $\mathcal{C}$ of $X$. Since $\operatorname{lip}(X)$ separates points uniformly, $\left\{\tau_{x}\right\}_{x \in \mathcal{C}}$ is a countable subset of $\operatorname{lip}(X)^{*}$. Let $\mathcal{Q}$ denote the subset of $\mathbb{K}$ such that the real and imaginary parts are rational numbers. Note that $\mathcal{Q}$ is a countable dense subset of $\mathbb{K}$. Put

$$
\text { L.h. } \mathcal{Q}\left\{\tau_{x}\right\}_{x \in \mathcal{C}}:=\left\{\sum_{k=1}^{N} \beta_{k} \tau_{x_{k}}: N \in \mathbb{N}, \beta_{k} \in \mathcal{Q}, x_{k} \in \mathcal{C}(k=1, \ldots, N)\right\}
$$

and

$$
\text { L.h. } \mathbb{K}\left\{\tau_{x}\right\}_{x \in X}:=\left\{\sum_{k=1}^{N} \beta_{k} \tau_{x_{k}}: N \in \mathbb{N}, \beta_{k} \in \mathbb{K}, x_{k} \in X(k=1, \ldots, N)\right\} .
$$

It follows from the countability of $\left\{\tau_{x}\right\}_{x \in \mathcal{C}}$ and $\mathcal{Q}$ that L.h. $\mathcal{Q}\left\{\tau_{x}\right\}_{x \in \mathcal{C}}$ is a countable subset of $\operatorname{lip}(X)^{*}$. By using the density of $\mathcal{C}$ and $\mathcal{Q}$, we see that the closure of L.h. $\mathcal{Q}\left\{\tau_{x}\right\}_{x \in \mathcal{C}}$ with respect to the norm $\|\cdot\|_{\operatorname{lip}(X)^{*}}$ contains L.h. $\mathbb{K}_{\mathbb{K}}\left\{\tau_{x}\right\}_{x \in X}$. Since L.h. $\mathbb{K}_{\mathbb{K}}\left\{\tau_{x}\right\}_{x \in X}$ is a dense subset of $\operatorname{lip}(X)^{*}$ (see e.g. [10, Theorem 3.3.3]), L.h. $\mathcal{Q}\left\{\tau_{x}\right\}_{x \in \mathcal{C}}$ is a countable dense subset of $\operatorname{lip}(X)^{*}$.

The next proposition implies that the norm of $\operatorname{lip}(X, E)^{*}$ is the cross norm on algebraic tensor product $E^{*} \otimes \operatorname{lip}(X)^{*}$.

Proposition 2.3. Let $e^{*} \in E^{*}$ and $h^{*} \in \operatorname{lip}(X)^{*}$. A functional $e^{*} \otimes h^{*}$ on $\operatorname{lip}(X, E)$ defined by

$$
\left(e^{*} \otimes h^{*}\right)(f)=h^{*}\left(e^{*} \circ f\right) \quad(f \in \operatorname{lip}(X, E))
$$

satisfies $e^{*} \otimes h^{*} \in \operatorname{lip}(X, E)^{*}$ and $\left\|e^{*} \otimes h^{*}\right\|_{\operatorname{lip}(X, E)^{*}}=\left\|e^{*}\right\|_{E^{*}}\left\|h^{*}\right\|_{\operatorname{lip}(X)^{*}}$.

Proof. Let $f \in \operatorname{lip}(X, E)$ be arbitrary. By Proposition 2.1, we have

$$
\left|\left(e^{*} \otimes h^{*}\right)(f)\right| \leq\left\|h^{*}\right\|_{\operatorname{lip}(X)^{*}}\left\|e^{*} \circ f\right\|_{\max } \leq\left\|h^{*}\right\|_{\operatorname{lip}(X)^{*}}\left\|e^{*}\right\|_{E^{*}}\|f\|_{\max } .
$$

Therefore, we have $e^{*} \otimes h^{*} \in \operatorname{lip}(X, E)^{*}$ and $\left\|e^{*} \otimes h^{*}\right\|_{\operatorname{lip}(X, E)^{*}} \leq\left\|e^{*}\right\|_{E^{*}}\left\|h^{*}\right\|_{\operatorname{lip}(X)^{*}}$. 
Let $e \in E$ and $h \in \operatorname{lip}(X)$ be arbitrary. Put $f(x):=h(x) e(x \in X)$. Then, $f \in \operatorname{lip}(X, E)$ and $\|f\|_{\max }=\|e\|_{E}\|h\|_{\max }$. Since the equation $\left(e^{*} e\right) h=e^{*} \circ f$ holds on $X$, we have

$$
\begin{aligned}
\left|e^{*} e\right|\left|h^{*} h\right| & =\left|h^{*}\left(\left(e^{*} e\right) h\right)\right|=\left|h^{*}\left(e^{*} \circ f\right)\right| \\
& =\left|\left(e^{*} \otimes h^{*}\right)(f)\right| \leq\left\|e^{*} \otimes h^{*}\right\|_{\operatorname{lip}(X, E)^{*}}\|e\|_{E}\|h\|_{\max } .
\end{aligned}
$$

Therefore, we have $\left\|e^{*}\right\|_{E^{*}}\left\|h^{*}\right\|_{\operatorname{lip}(X)^{*}} \leq\left\|e^{*} \otimes h^{*}\right\|_{\operatorname{lip}(X, E)^{*}}$ and $\left\|e^{*} \otimes h^{*}\right\|_{\operatorname{lip}(X, E)^{*}}=$ $\left\|e^{*}\right\|_{E^{*}}\left\|h^{*}\right\|_{\operatorname{lip}(X)^{*} \text {. }}$

Finally, we prove the following proposition.

Proposition 2.4. If $\operatorname{lip}(X)$ separates points uniformly, then $E^{*} \otimes \operatorname{lip}(X)^{*}$ is dense in $\operatorname{lip}(X, E)^{*}$.

This proposition can be proved by tracing a method in [4]. If $\operatorname{lip}(X)$ separates points uniformly, then we have

$$
E^{*} \otimes\left\{\tau_{x}\right\}_{x \in X} \subset E^{*} \otimes \operatorname{lip}(X)^{*} \subset \operatorname{lip}(X, E)^{*} .
$$

Therefore, to prove Proposition 2.4, we show that $E^{*} \otimes\left\{\tau_{x}\right\}_{x \in X}$ is dense in $\operatorname{lip}(X, E)^{*}$ if $\operatorname{lip}(X)$ separates the points uniformly.

Let us introduce some notation. Set

$$
\begin{aligned}
\Delta & :=\left\{\left(x, x^{\prime}\right) \in X \times X: x=x^{\prime}\right\}, \\
W & :=(X \times X) \backslash \Delta, \\
K & :=X \cup W,
\end{aligned}
$$

so that $K$ is a locally compact space. Let $C_{0}(K, E)$ denote the Banach space of $E$-valued continuous functions that vanish at infinity. We embed $\operatorname{lip}(X, E)$ in $C_{0}(K, E)$ in the usual way:

$$
\begin{aligned}
\tilde{f}(x) & :=f(x) \quad(x \in X), \\
\tilde{f}\left(x, x^{\prime}\right) & :=\frac{f(x)-f\left(x^{\prime}\right)}{d\left(x, x^{\prime}\right)} \quad\left(\left(x, x^{\prime}\right) \in W\right), \\
\tilde{f}(\omega) & :=0,
\end{aligned}
$$

where $\omega$ is the point at infinity. Hence $\operatorname{lip}(X, E)$ can be considered as a subspace of $C\left(K_{\omega}, E\right)$, where $K_{\omega}$ is the one-point compactification of $K$.

Let $Y$ be a compact Hausdorff space. Then $C(Y, E)^{*}$ is isometrically isomorphic to $M\left(Y, E^{*}\right)$, where $M\left(Y, E^{*}\right)$ is the Banach space of $E^{*}$-valued countably additive regular Borel measures on $Y$ with finite variation (see e.g. [2, Theorem 1.7.1]).

Let $\mu \in M\left(X, E^{*}\right)$. A functional $f_{\mu}^{*}$ on $\operatorname{lip}(X, E)$ defined by

$$
f_{\mu}^{*} f:=\int_{X} f(x) d \mu(x) \quad(f \in \operatorname{lip}(X, E))
$$

satisfies $f_{\mu}^{*} \in \operatorname{lip}(X, E)^{*}$. Set

$$
\mathcal{N}:=\left\{f_{\mu}^{*}: \mu \in M\left(X, E^{*}\right) \text { and } f_{\mu}^{*} \text { is represented as (2) }\right\} .
$$

Clearly, if $\operatorname{lip}(X)$ separates points uniformly, then $E^{*} \otimes\left\{\tau_{x}\right\}_{x \in X}$ is contained in $\mathcal{N}$.

To prove Proposition 2.4, we first show the following proposition. 
Proposition 2.5. $\mathcal{N}$ is dense in $\operatorname{lip}(X, E)^{*}$.

Proof. Let $f^{*} \in \operatorname{lip}(X, E)^{*}$ be arbitrary. By using the Hahn-Banach theorem, there exists $\mu \in M\left(K_{\omega}, E^{*}\right)$ such that

$$
f^{*} f=\int_{K_{\omega}} \tilde{f}(\boldsymbol{x}) d \mu(\boldsymbol{x}) \quad(f \in \operatorname{lip}(X, E)) .
$$

Fix a point $x_{0} \in X$. For each $n=1,2,3, \ldots$, set

$$
X_{n}:=\left\{x \in X: d\left(x, x_{0}\right) \leq n\right\}
$$

and

$$
W_{n}:=\left\{\left(x, x^{\prime}\right) \in W: x, x^{\prime} \in X_{n} \text { and } d\left(x, x^{\prime}\right) \geq 1 /(n+1)\right\} .
$$

Put $K_{n}:=X_{n} \cup W_{n}$. Then, $\left\{K_{n}\right\}_{n=1}^{\infty}$ is an increasing sequence of compact sets whose union is $K$. For each $n=1,2,3, \ldots$, put

$$
f_{n}^{*} f:=\int_{K_{n}} \tilde{f}(\boldsymbol{x}) d \mu(\boldsymbol{x}) \quad(f \in \operatorname{lip}(X, E)) .
$$

Let $f \in \operatorname{lip}(X, E)$ be arbitrary. By noting that $\tilde{f}(\omega)=0$ and $K \backslash K_{n} \subset K \subset K_{\omega}=K \cup\{\omega\}$, we have

$$
\begin{aligned}
\left|f^{*} f-f_{n}^{*} f\right| & =\left|\int_{K_{\omega}} \tilde{f}(\boldsymbol{x}) d \mu(\boldsymbol{x})-\int_{K_{n}} \tilde{f}(\boldsymbol{x}) d \mu(\boldsymbol{x})\right| \\
& =\left|\int_{K_{\omega} \backslash K_{n}} \tilde{f}(\boldsymbol{x}) d \mu(\boldsymbol{x})\right| \leq \int_{K_{\omega} \backslash K_{n}}\|\tilde{f}(\boldsymbol{x})\|_{E} d|\mu|(\boldsymbol{x}) \\
& \leq \int_{\left(K \backslash K_{n}\right) \cup\{\omega\}}\|\tilde{f}(\boldsymbol{x})\|_{E} d|\mu|(\boldsymbol{x})=\int_{K \backslash K_{n}}\|\tilde{f}(\boldsymbol{x})\|_{E} d|\mu|(\boldsymbol{x}) \\
& \leq|\mu|\left(K \backslash K_{n}\right)\left(\sup _{\boldsymbol{x} \in K \backslash K_{n}}\|\tilde{f}(\boldsymbol{x})\|_{E}\right) \leq|\mu|\left(K \backslash K_{n}\right)\left(\sup _{\boldsymbol{x} \in K_{\omega}}\|\tilde{f}(\boldsymbol{x})\|_{E}\right) \\
& \leq|\mu|\left(K \backslash K_{n}\right)\|f\|_{\max },
\end{aligned}
$$

where $|\mu|$ is the variation of $\mu$. Hence we have

$$
\left\|f_{n}^{*}-f^{*}\right\|_{\operatorname{lip}(X, E)^{*}} \leq|\mu|\left(K \backslash K_{n}\right) .
$$

Since $|\mu|$ is countably additive, we have $|\mu|\left(K \backslash K_{n}\right)=|\mu|(K)-|\mu|\left(K_{n}\right) \quad(n=$ $1,2,3, \ldots)$. By noting that $|\mu|$ is finite, that $\bigcup_{n=1}^{\infty} K_{n}=K$ and that $\left\{K_{n}\right\}_{n=1}^{\infty}$ is increasing, we have $|\mu|\left(K \backslash K_{n}\right) \rightarrow 0$ as $n \rightarrow \infty$. Therefore, we have $\left\|f_{n}^{*}-f^{*}\right\|_{\operatorname{lip}(X, E)^{*}} \rightarrow 0$ as $n \rightarrow$ $\infty$. We next show that $f_{n}^{*} \in \mathcal{N}$. For any $f \in \operatorname{lip}(X, E)$, we have

$$
\begin{aligned}
f_{n}^{*} f & =\int_{X_{n}} f(x) d \mu(x)+\int_{W_{n}} \tilde{f}\left(x, x^{\prime}\right) d \mu\left(x, x^{\prime}\right) \\
& =\int_{X_{n}} f(x) d \mu(x)+\int_{W_{n}} \frac{f(x)}{d\left(x, x^{\prime}\right)} d \mu\left(x, x^{\prime}\right)-\int_{W_{n}} \frac{f\left(x^{\prime}\right)}{d\left(x, x^{\prime}\right)} d \mu\left(x, x^{\prime}\right) .
\end{aligned}
$$


Since $d\left(x, x^{\prime}\right)$ is bounded away from zero on $W_{n}$, there exist $\mu_{1}, \mu_{2} \in M\left(X, E^{*}\right)$ with support contained in $X_{n}$ such that

$$
\int_{W_{n}} \frac{f(x)}{d\left(x, x^{\prime}\right)} d \mu\left(x, x^{\prime}\right)=\int_{X_{n}} f(x) d \mu_{1}(x)
$$

and

$$
\int_{W_{n}} \frac{f\left(x^{\prime}\right)}{d\left(x, x^{\prime}\right)} d \mu\left(x, x^{\prime}\right)=\int_{X_{n}} f(x) d \mu_{2}(x) .
$$

Hence we have

$$
f_{n}^{*} f=\int_{X_{n}} f(x) d\left(\mu+\mu_{1}-\mu_{2}\right)(x) .
$$

Therefore, we have $f_{n}^{*} \in \mathcal{N}$.

Next, we prove the following proposition.

Proposition 2.6. If $\operatorname{lip}(X)$ separates points uniformly, then $E^{*} \otimes\left\{\tau_{x}\right\}_{x \in X}$ is dense in $\mathcal{N}$.

Proof. Let $f_{\mu}^{*} \in \mathcal{N}$ and $\gamma>0$ be arbitrary, and let supp $\mu$ denote the support of $\mu$. By noting that $X$ is compact and that supp $\mu$ is closed in $X$, there exist $x_{1}^{\prime}, \ldots, x_{N}^{\prime} \in \operatorname{supp} \mu$ such that $\operatorname{supp} \mu \subset \bigcup_{j=1}^{N} B_{j}$, where $B_{j}:=\left\{x \in X:=d\left(x, x_{j}^{\prime}\right)<\gamma /(4|\mu|(\operatorname{supp} \mu))\right\}$. Set

$$
\begin{aligned}
& A_{1}:=B_{1}, \\
& A_{j}:=B_{j} \backslash \bigcup_{i=1}^{j-1} B_{i} \quad(j=2, \ldots, N) .
\end{aligned}
$$

Then $\left\{A_{j}\right\}_{j=1}^{N}$ is a disjoint collection of Borel sets such that supp $\mu \subset \bigcup_{j=1}^{N} A_{j}$ and $A_{j} \subset$ $B_{j}(j=1, \ldots, N)$. We may assume that $A_{j} \neq \emptyset(j=1, \ldots, N)$ without loss of generality. Then, for each $j=1, \ldots, N$, we can choose $x_{j} \in A_{j}$. Set

$$
f^{*}:=\sum_{j=1}^{N} \mu\left(A_{j}\right) \otimes \tau_{x_{j}} .
$$

Then $f^{*} \in E^{*} \otimes\left\{\tau_{x}\right\}_{x \in X}$. Let $f \in \operatorname{lip}(X, E)$ with $\|f\|_{\max } \leq 1$ be arbitrary. Set

$$
g:=\sum_{j=1}^{N} f\left(x_{j}\right) \chi_{A_{j}},
$$

where $\chi_{A_{j}}$ is the characteristic function on $A_{j}$. For any $x \in \operatorname{supp} \mu$, there exists a unique $i \in\{1, \ldots, N\}$ such that $x \in A_{i}$. By noting that $A_{i} \subset B_{i}$, we have

$$
\begin{aligned}
\|g(x)-f(x)\|_{E} & =\left\|f\left(x_{i}\right)-f(x)\right\|_{E} \leq d\left(x_{i}, x\right) \\
& \leq d\left(x_{i}, x_{i}^{\prime}\right)+d\left(x_{i}^{\prime}, x\right)<\frac{\gamma}{2|\mu|(\operatorname{supp} \mu)} .
\end{aligned}
$$

Therefore, we have

$$
\sup _{x \in \operatorname{supp} \mu}\|g(x)-f(x)\|_{E} \leq \frac{\gamma}{2|\mu|(\operatorname{supp} \mu)} .
$$


Since

$$
\int_{X} g(x) d \mu(x)=\sum_{j=1}^{N}\left(\mu\left(A_{j}\right)\right)\left(f\left(x_{j}\right)\right)=\sum_{j=1}^{N}\left(\mu\left(A_{j}\right) \otimes \tau_{x_{j}}\right)(f)=f^{*} f,
$$

we have

$$
\begin{aligned}
\left|f^{*} f-f_{\mu}^{*} f\right| & =\left|\int_{X} g(x) d \mu(x)-\int_{X} f d \mu(x)\right|=\left|\int_{X}(g-f)(x) d \mu(x)\right| \\
& \leq \int_{X}\|g(x)-f(x)\|_{E} d|\mu|(x)=\int_{\operatorname{supp} \mu}\|g(x)-f(x)\|_{E} d|\mu|(x) \\
& \leq|\mu|(\operatorname{supp} \mu)\left(\sup _{x \in \operatorname{supp} \mu}\|g(x)-f(x)\|_{E}\right) \leq \frac{\gamma}{2} .
\end{aligned}
$$

Hence we have

$$
\left\|f^{*}-f_{\mu}^{*}\right\|_{\operatorname{lip}(X, E)^{*}}<\gamma .
$$

Therefore, $E^{*} \otimes\left\{\tau_{x}\right\}_{x \in X}$ is dense in $\mathcal{N}$.

Propositions 2.5 and 2.6 imply that $E^{*} \otimes\left\{\tau_{x}\right\}_{x \in X}$ is dense in $\operatorname{lip}(X, E)^{*}$ if $\operatorname{lip}(X)$ separates points uniformly. Therefore, $E^{*} \otimes \operatorname{lip}(X)^{*}$ is dense in $\operatorname{lip}(X, E)^{*}$ if $\operatorname{lip}(X)$ separates points uniformly.

\section{Proof of Theorem 1}

In this section, we prove Theorem 1. To prove it, let us introduce some notation. For any Banach spaces $A$ and $B, A \otimes_{\varepsilon} B$ and $A \otimes_{\pi} B$ denote the algebraic tensor product of $A$ and $B$ with injective cross norm $\varepsilon$ and projective cross norm $\pi$, respectively. Let $A \widehat{\otimes}_{\varepsilon} B$ and $A \widehat{\otimes}_{\pi} B$ denote the completion of $A \otimes_{\varepsilon} B$ and $A \otimes_{\pi} B$ with respect to the cross norms $\varepsilon$ and $\pi$, respectively.

Also, let us introduce several conditions as follows:

(A1) $\operatorname{lip}(X)$ separates the points uniformly;

(A2) either $\operatorname{lip}(X)^{*}$ or $E^{*}$ has the approximation property.

By Proposition 2.2, the condition (A1) implies that lip $(X)^{*}$ has the Radon-Nikodým property.

By using [7, Theorem 5.33], we get the following lemma.

LEMma 3.1. Suppose (A1) and (A2) hold. Then $E^{*} \widehat{\otimes}_{\pi} \operatorname{lip}(X)^{*}$ is isometrically isomorphic to $\left(E \widehat{\otimes}_{\varepsilon} \operatorname{lip}(X)\right)^{*}$. Moreover, if $T: E^{*} \widehat{\otimes}_{\pi} \operatorname{lip}(X)^{*} \rightarrow\left(E \widehat{\otimes}_{\varepsilon} \operatorname{lip}(X)\right)^{*}$ is an isometric isomorphism, then $T$ satisfies

$$
\left(T\left(\sum_{j=1}^{N} e_{j}^{*} \otimes h_{j}^{*}\right)\right)\left(\sum_{i=1}^{M} e_{i} \otimes h_{i}\right)=\sum_{j=1}^{N} \sum_{i=1}^{M}\left(e_{j}^{*} e_{i}\right)\left(h_{j}^{*} h_{i}\right)
$$

for any $\sum_{j=1}^{N} e_{j}^{*} \otimes h_{j}^{*} \in E^{*} \otimes_{\pi} \operatorname{lip}(X)^{*}$ and $\sum_{i=1}^{M} e_{i} \otimes h_{i} \in E \otimes_{\varepsilon} \operatorname{lip}(X)$.

By Lemma 3.1, $\left(E \widehat{\otimes}_{\varepsilon} \operatorname{lip}(X)\right)^{* *}$ is isometrically isomorphic to $\left(E^{*} \widehat{\otimes}_{\pi} \operatorname{lip}(X)^{*}\right)^{*}$. 
Lemma 3.2. The mapping $U_{0}: E \otimes_{\varepsilon} \operatorname{lip}(X) \rightarrow \operatorname{lip}(X, E)$ defined by

$$
\left(U_{0} z\right)(x):=\sum_{i=1}^{M} h_{i}(x) e_{i} \quad\left(z=\sum_{i=1}^{M} e_{i} \otimes h_{i} \in E \otimes_{\varepsilon} \operatorname{lip}(X), x \in X\right)
$$

is a linear isometry.

Proof. Let $z=\sum_{i=1}^{M} e_{i} \otimes h_{i} \in E \otimes_{\varepsilon} \operatorname{lip}(X)$ be arbitrary. Then we have

$$
\begin{aligned}
\left\|U_{0} z\right\|_{C(X, E)} & =\sup _{x \in X}\left|\sum_{i=1}^{M} h_{i}(x) e_{i} \|_{E}=\sup _{x \in X} \sup _{\substack{e^{*} \in E^{*} \\
\left\|e^{*}\right\|_{E^{*} \leq 1}}}\right| e^{*}\left(\sum_{i=1}^{M} h_{i}(x) e_{i}\right) \mid \\
& =\sup _{\substack{e^{*} \in E^{*} \\
\left\|e^{*}\right\|_{E^{*} \leq 1}}} \sup _{x \in X}\left|\sum_{i=1}^{M}\left(e^{*} e_{i}\right) h_{i}(x)\right|=\sup _{\substack{e^{*} \in E^{*} \\
\left\|e^{*}\right\|_{E^{*} \leq 1}}}\left\|\sum_{i=1}^{M}\left(e^{*} e_{i}\right) h_{i}\right\|_{C(X)}
\end{aligned}
$$

and

$$
\begin{aligned}
\mathcal{L}_{X, E}\left(U_{0} z\right)= & \sup _{\substack{x, x^{\prime} \in X \\
x \neq x^{\prime}}} \frac{\left\|\sum_{i=1}^{M} h_{i}(x) e_{i}-\sum_{i=1}^{M} h_{i}\left(x^{\prime}\right) e_{i}\right\|_{E}}{d\left(x, x^{\prime}\right)} \\
= & \sup _{\substack{x, x^{\prime} \in X \\
x \neq x^{\prime}}} \sup _{\substack{e^{*} \in E^{*} \\
\left\|e^{*}\right\|_{E^{*} \leq 1}}} \frac{\left|e^{*}\left(\sum_{i=1}^{M} h_{i}(x) e_{i}-\sum_{i=1}^{M} h_{i}\left(x^{\prime}\right) e_{i}\right)\right|}{d\left(x, x^{\prime}\right)} \\
= & \sup _{\substack{e^{*} \in E^{*} \\
\left\|e^{*}\right\|_{E^{*} \leq 1}}} \sup _{\substack{x, x^{\prime} \in X \\
x \neq x^{\prime}}} \frac{\left|\sum_{i=1}^{M}\left(e^{*} e_{i}\right) h_{i}(x)-\sum_{i=1}^{M}\left(e^{*} e_{i}\right) h_{i}\left(x^{\prime}\right)\right|}{d\left(x, x^{\prime}\right)} \\
& =\sup _{\substack{e^{*} \in E^{*} \\
\left\|e^{*}\right\|_{E^{*}} \leq 1}} \mathcal{L}_{X, \mathbb{K}}\left(\sum_{i=1}^{M}\left(e^{*} e_{i}\right) h_{i}\right) .
\end{aligned}
$$

By using equations (5) and (6), we have

$$
\begin{aligned}
\left\|U_{0} z\right\|_{\max }= & \max \left\{\sup _{\substack{e^{*} \in E^{*} \\
\left\|e^{*}\right\|_{E^{*} \leq 1}}}\left\|\sum_{i=1}^{M}\left(e^{*} e_{i}\right) h_{i}\right\|_{C(X)}, \sup _{\substack{e^{*} \in E^{*} \\
\left\|e^{*}\right\|_{E^{*} \leq 1}}} \mathcal{L}_{X, \mathbb{K}}\left(\sum_{i=1}^{M}\left(e^{*} e_{i}\right) h_{i}\right)\right\} \\
= & \sup _{\substack{e^{*} \in E^{*} \\
\left\|e^{*}\right\|_{E^{*} \leq 1}}} \max \left\{\left\|\sum_{i=1}^{M}\left(e^{*} e_{i}\right) h_{i}\right\|_{C(X)}, \mathcal{L}_{X, \mathbb{K}}\left(\sum_{i=1}^{M}\left(e^{*} e_{i}\right) h_{i}\right)\right\} \\
= & \sup _{\substack{e^{*} \in E^{*} \\
\left\|e^{*}\right\|_{E^{*} \leq 1}}}\left\|\sum_{i=1}^{M}\left(e^{*} e_{i}\right) h_{i}\right\|_{\max }=\varepsilon(z) .
\end{aligned}
$$

Therefore, $U_{0}$ is a linear isometry.

By noting that $E \widehat{\otimes}_{\varepsilon} \operatorname{lip}(X)$ is the completion of $E \otimes_{\varepsilon} \operatorname{lip}(X)$, there exists a unique linear isometry $U: E \widehat{\otimes}_{\varepsilon} \operatorname{lip}(X) \rightarrow \operatorname{lip}(X, E)$ such that

$$
U z=U_{0} z \quad\left(z \in E \otimes_{\varepsilon} \operatorname{lip}(X)\right) .
$$


LEMMA 3.3. Suppose (A1) and (A2) hold. Then $U$ is an isometric isomorphism from $E \widehat{\otimes}_{\varepsilon} \operatorname{lip}(X)$ to $\operatorname{lip}(X, E)$.

Proof. It is sufficient to show that $U$ is surjective. Let $\operatorname{ran}(U)$ denote the range of $U$. Clearly, $\operatorname{ran}(U)$ is a closed subspace of $\operatorname{lip}(X, E)$. Here, we show that $\operatorname{ran}(U)$ is dense in $\operatorname{lip}(X, E)$. Note that $E^{*} \otimes \operatorname{lip}(X)^{*}$ is a subspace of $\left(E \widehat{\otimes}_{\varepsilon} \operatorname{lip}(X)\right)^{*}$ (see e.g. [7, Proposition 3.1(c)]), and that $\|\cdot\|_{\operatorname{lip}(X, E)^{*}}$ is the cross norm on $E^{*} \otimes \operatorname{lip}(X)^{*}$ by Proposition 2.3. It is easy to see that

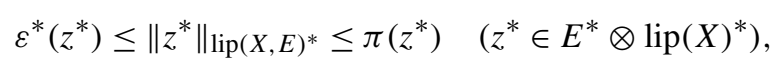

where $\varepsilon^{*}$ is the dual of the injective cross norm $\varepsilon$. By Lemma 3.1, we have

$$
\varepsilon^{*}\left(z^{*}\right)=\pi\left(z^{*}\right) \quad\left(z^{*} \in E^{*} \otimes \operatorname{lip}(X)^{*}\right) .
$$

By combining (8) and (9) we have

$$
\left\|z^{*}\right\|_{\operatorname{lip}(X, E)^{*}}=\pi\left(z^{*}\right) \quad\left(z^{*} \in E^{*} \otimes \operatorname{lip}(X)^{*}\right) .
$$

Therefore, the mapping

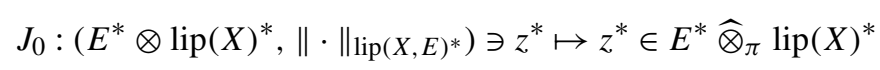

is a linear isometry. By using Proposition 2.4, there exists a unique linear isometry $J: \operatorname{lip}(X, E)^{*} \rightarrow E^{*} \widehat{\otimes}_{\pi} \operatorname{lip}(X)^{*}$ such that

$$
J z^{*}=J_{0} z^{*} \quad\left(z^{*} \in E^{*} \otimes \operatorname{lip}(X)^{*}\right) .
$$

Let $z^{*}=\sum_{j=1}^{N} e_{j}^{*} \otimes h_{j}^{*} \in E^{*} \otimes \operatorname{lip}(X)^{*}$ and $z=\sum_{i=1}^{M} e_{i} \otimes h_{i} \in E \otimes_{\varepsilon} \operatorname{lip}(X)$ be arbitrary. Then we have

$$
\begin{aligned}
\left(T J z^{*}\right)(z) & =\left(T z^{*}\right)(z)=\sum_{j=1}^{N} \sum_{i=1}^{M}\left(e_{j}^{*} e_{i}\right)\left(h_{j}^{*} h_{i}\right) \\
& =\sum_{j=1}^{N} h_{j}^{*}\left(\sum_{i=1}^{M}\left(e_{j}^{*} e_{i}\right) h_{i}\right)=\sum_{j=1}^{N} h_{j}^{*}\left(e_{j}^{*} \circ(U z)\right) \\
& =\sum_{j=1}^{N}\left(e_{j}^{*} \otimes h_{j}^{*}\right)(U z)=z^{*}(U z)=\left(U^{*} z^{*}\right)(z) .
\end{aligned}
$$

By noting that $E \widehat{\otimes}_{\varepsilon} \operatorname{lip}(X)$ is the completion of $E \otimes_{\varepsilon} \operatorname{lip}(X)$, and that $T J z^{*}$ and $U^{*} z^{*}$ are bounded on $E \widehat{\otimes}_{\varepsilon} \operatorname{lip}(X)$, the equation $T J z^{*}=U^{*} z^{*}$ holds on $E \widehat{\otimes}_{\varepsilon} \operatorname{lip}(X)$. By noting that $E^{*} \otimes \operatorname{lip}(X)^{*}$ is dense in $\operatorname{lip}(X, E)^{*}$ by Proposition 2.4 , and that $T J$ and $U^{*}$ are bounded on $\operatorname{lip}(X, E)^{*}$, the equation $T J=U^{*}$ holds on $\operatorname{lip}(X, E)^{*}$. Since $T: E^{*} \widehat{\otimes}_{\pi} \operatorname{lip}(X)^{*} \rightarrow\left(E \widehat{\otimes}_{\varepsilon} \operatorname{lip}(X)\right)^{*}$ and $J: \operatorname{lip}(X, E)^{*} \rightarrow E^{*} \widehat{\otimes}_{\pi} \operatorname{lip}(X)^{*}$ are isometries, respectively, $U^{*}: \operatorname{lip}(X, E)^{*} \rightarrow\left(E \widehat{\otimes}_{\varepsilon} \operatorname{lip}(X)\right)^{*}$ is an isometry. Therefore, $\operatorname{ran}(U)$ is dense in $\operatorname{lip}(X, E)$.

By Lemma 3.3, lip $(X, E)^{* *}$ is isometrically isomorphic to $\left(E \widehat{\otimes}_{\varepsilon} \operatorname{lip}(X)\right)^{* *}$.

For any Banach spaces $A$ and $B, \mathcal{B}(A, B)$ denotes the Banach space of all bounded operators from $A$ into $B$ with operator norm $\|\cdot\|_{\mathcal{B}(A, B)}$. 
LeMmA 3.4. Suppose (Al) holds. Then $\left(E^{*} \widehat{\otimes}_{\pi} \operatorname{lip}(X)^{*}\right)^{*}$ is isometrically isomorphic to $\mathscr{B}\left(E^{*}, \operatorname{Lip}(X)\right)$.

Proof. By using [5, Corollary 1.22] hold, $\left(E^{*} \widehat{\otimes}_{\pi} \operatorname{lip}(X)^{*}\right)^{*}$ is isometrically isomorphic to $\mathcal{B}\left(E^{*}, \operatorname{lip}(X)^{* *}\right)$. Suppose that $\Psi:\left(E^{*} \widehat{\otimes}_{\pi} \operatorname{lip}(X)^{*}\right)^{*} \rightarrow \mathcal{B}\left(E^{*}, \operatorname{lip}(X)^{* *}\right)$ is an isometric isomorphism. Then $\Psi$ is of the form

$$
\left(\left(\Psi f^{* *}\right)\left(e^{*}\right)\right)\left(h^{*}\right)=f^{* *}\left(e^{*} \otimes h^{*}\right)
$$

for any $f^{* *} \in\left(E^{*} \widehat{\otimes}_{\pi} \operatorname{lip}(X)^{*}\right)^{*}, e^{*} \in E^{*}$ and $h^{*} \in \operatorname{lip}(X)^{*}$ (see e.g. [5, Theorem 1.21 and Corollary 1.22]).

By Theorem $\mathrm{A}, \mathscr{B}\left(E^{*}, \operatorname{lip}(X)^{* *}\right)$ is isometrically isomorphic to $\mathscr{B}\left(E^{*}, \operatorname{Lip}(X)\right)$, via the map $\Phi: \mathscr{B}\left(E^{*}, \operatorname{lip}(X)^{* *}\right) \rightarrow \mathscr{B}\left(E^{*}, \operatorname{Lip}(X)\right)$ defined by

$$
\left((\Phi A)\left(e^{*}\right)\right)(x):=\left(A e^{*}\right)\left(\tau_{x}\right)
$$

for any $A \in \mathscr{B}\left(E^{*}, \operatorname{lip}(X)^{* *}\right), e^{*} \in E^{*}$ and $x \in X$.

Set $S:=\Phi \Psi$. Since $\Phi$ and $\Psi$ are isometric isomorphisms, $S$ is an isometric isomorphism from $\left(E^{*} \widehat{\otimes}_{\pi} \operatorname{lip}(X)^{*}\right)^{*}$ to $\mathscr{B}\left(E^{*}, \operatorname{Lip}(X)\right)$.

Lemma 3.5. $\mathcal{B}\left(E^{*}, \operatorname{Lip}(X)\right)$ is isometrically isomorphic to $\operatorname{Lip}\left(X, E^{* *}\right)$.

Proof. The mapping $R: \mathcal{B}\left(E^{*}, \operatorname{Lip}(X)\right) \rightarrow \operatorname{Lip}\left(X, E^{* *}\right)$ is defined by

$$
((R A)(x))\left(e^{*}\right):=\left(A e^{*}\right)(x) \quad\left(A \in \mathscr{B}\left(E^{*}, \operatorname{Lip}(X)\right), x \in X, e^{*} \in E^{*}\right) .
$$

Then,

$$
\|R A\|_{C\left(X, E^{* *}\right)}=\sup _{x \in X} \sup _{\substack{e^{*} \in E^{*} \\\left\|e^{*}\right\|_{E^{*}} \leq 1}}\left|\left(A e^{*}\right)(x)\right|=\sup _{\substack{e^{*} \in E^{*} \\\left\|e^{*}\right\|_{E^{*}} \leq 1}}\left\|A e^{*}\right\|_{C(X)}
$$

and

$$
\mathcal{L}_{X, E^{* *}}(R A)=\sup _{\substack{x, x^{\prime} \in X \\ x \neq x^{\prime}}} \sup _{\substack{e^{*} \in E^{*} \\\left\|e^{*}\right\|_{E^{*}} \leq 1}} \frac{\left|\left(A e^{*}\right)(x)-\left(A e^{*}\right)\left(x^{\prime}\right)\right|}{d_{X}\left(x, x^{\prime}\right)}=\sup _{\substack{e^{*} \in E^{*} \\\left\|e^{*}\right\|_{E^{*}} \leq 1}} \mathcal{L}_{X, \mathbb{K}}\left(A e^{*}\right) .
$$

Therefore, we have

$$
\begin{aligned}
\|R A\|_{\max }= & \max \left\{\|R A\|_{C\left(X, E^{* *}\right)}, \mathcal{L}_{X, E^{* *}}(R A)\right\} \\
= & \max \left\{\sup _{\substack{e^{*} \in E^{*} \\
\left\|e^{*}\right\|_{E^{*} \leq 1}}}\left\|A e^{*}\right\|_{C(X)}, \sup _{\substack{e^{*} \in E^{*} \\
\left\|e^{*}\right\|_{E^{*} \leq 1}}} \mathcal{L}_{X, \mathbb{K}}\left(A e^{*}\right)\right\} \\
= & \sup _{\substack{e^{*} \in E^{*} \\
\left\|e^{*}\right\|_{E^{*}} \leq 1}} \max \left\{\left\|A e^{*}\right\|_{C(X)}, \mathcal{L}_{X, \mathbb{K}}\left(A e^{*}\right)\right\}=\|A\|_{\mathcal{B}\left(E^{*}, \operatorname{Lip}(X)\right) .}
\end{aligned}
$$

Hence, $R$ is a linear isometry. Let $g \in \operatorname{Lip}\left(X, E^{* *}\right)$. The mapping $A: E^{*} \rightarrow \operatorname{Lip}(X)$ is defined by

$$
\left(A e^{*}\right)(x)=(g(x))\left(e^{*}\right) \quad\left(e^{*} \in E^{*}, x \in X\right) .
$$


It is clear that $A$ is a linear operator. Also, we have

$$
\begin{aligned}
\sup _{\substack{e^{*} \in E^{*} \\
\left\|e^{*}\right\|_{E^{*} \leq 1}}}\left\|A e^{*}\right\|_{C(X)} & =\sup _{x \in X} \sup _{\substack{e^{*} \in E^{*} \\
\left\|e^{*}\right\|_{E^{*} \leq 1}}}\left|\left(A e^{*}\right)(x)\right|=\sup _{x \in X} \sup _{\substack{e^{*} \in E^{*} \\
\left\|e^{*}\right\|_{E^{*} \leq 1}}}\left|(g(x))\left(e^{*}\right)\right| \\
& =\sup _{x \in X}\|g(x)\|_{E^{* *}}=\|g\|_{C\left(X, E^{* *}\right)}
\end{aligned}
$$

and

$$
\begin{aligned}
\sup _{\substack{e^{*} \in E^{*} \\
\left\|e^{*}\right\|_{E^{*}} \leq 1}} \mathcal{L}_{X, \mathbb{K}}\left(A e^{*}\right) & =\sup _{\substack{x, x^{\prime} \in X \\
x \neq x^{\prime}}} \sup _{\substack{e^{*} \in E^{*} \\
\left\|e^{*}\right\|_{E^{*} \leq 1}}} \frac{\left|\left(A e^{*}\right)(x)-\left(A e^{*}\right)\left(x^{\prime}\right)\right|}{d_{X}\left(x, x^{\prime}\right)} \\
& =\sup _{\substack{x, x^{\prime} \in X \\
x \neq x^{\prime}}} \sup _{\substack{e^{*} \in E^{*} \\
\left\|e^{*}\right\|_{E^{*} \leq 1}}} \frac{\left|(g(x))\left(e^{*}\right)-\left(g\left(x^{\prime}\right)\right)\left(e^{*}\right)\right|}{d_{X}\left(x, x^{\prime}\right)} \\
& =\sup _{\substack{x, x^{\prime} \in X \\
x \neq x^{\prime}}} \frac{\left\|(g(x))-\left(g\left(x^{\prime}\right)\right)\right\|_{E^{* *}}}{d_{X}\left(x, x^{\prime}\right)}=\mathcal{L}_{X, E^{* *}}(g) .
\end{aligned}
$$

Equations (13) and (14) show that

$$
\begin{aligned}
\|A\|_{\mathcal{B}\left(E^{*}, \operatorname{Lip}(X)\right)} & =\max \left\{\sup _{\substack{e^{*} \in E^{*} \\
\left\|e^{*}\right\|_{E^{*} \leq 1}}}\left\|A e^{*}\right\|_{C(X)}, \sup _{\substack{e^{*} \in E^{*} \\
\left\|e^{*}\right\|_{E^{*} \leq 1}}} \mathcal{L}_{X, \mathbb{K}}\left(A e^{*}\right)\right\} \\
& =\max \left\{\|g\|_{C\left(X, E^{* *}\right)}, \mathcal{L}_{X, E^{* *}}(g)\right\}=\|g\|_{\max } .
\end{aligned}
$$

Therefore, we have $A \in \mathscr{B}\left(E^{*}, \operatorname{Lip}(X)\right)$. Also, we have

$$
((R A)(x))\left(e^{*}\right)=\left(A e^{*}\right)(x)=(g(x))\left(e^{*}\right)
$$

for any $x \in X$ and $e^{*} \in E^{*}$. Hence, $R$ is an isometric isomorphism from $\mathcal{B}\left(E^{*}, \operatorname{Lip}(X)\right)$ to $\operatorname{Lip}\left(X, E^{* *}\right)$.

Proof of Theorem 1. Put

$$
Q f^{* *}:=R S T^{*}\left(U^{-1}\right)^{* *} f^{* *} \quad\left(f^{* *} \in \operatorname{lip}(X, E)^{* *}\right),
$$

where $R, S, T$ and $U$ are as in the above lemmas. Since $R, S, T^{*}$ and $\left(U^{-1}\right)^{* *}$ are isometric isomorphisms, $Q$ is an isometric isomorphism from $\operatorname{lip}(X, E)^{* *}$ to $\operatorname{Lip}\left(X, E^{* *}\right)$. Therefore, $\operatorname{lip}(X, E)^{* *}$ is isometrically isomorphic to $\operatorname{Lip}\left(X, E^{* *}\right)$.

Next, we compute $Q f^{* *}$ for any $f^{* *} \in \operatorname{lip}(X, E)^{* *}$. By using equations (10), (11) and (12), we have

$$
\begin{aligned}
\left(\left(Q f^{* *}\right)(x)\right)\left(e^{*}\right) & =\left(\left(R S T^{*}\left(U^{-1}\right)^{* *} f^{* *}\right)(x)\right)\left(e^{*}\right)=\left(\left(S T^{*}\left(U^{-1}\right)^{* *} f^{* *}\right)\left(e^{*}\right)\right)(x) \\
& =\left(T^{*}\left(U^{-1}\right)^{* *} f^{* *}\right)\left(e^{*} \otimes \tau_{x}\right)=\left(\left(U^{-1}\right)^{* *} f^{* *}\right)\left(T\left(e^{*} \otimes \tau_{x}\right)\right) \\
& =f^{* *}\left(\left(U^{-1}\right)^{*} T\left(e^{*} \otimes \tau_{x}\right)\right)
\end{aligned}
$$

for any $f^{* *} \in \operatorname{lip}(X, E)^{* *}, x \in X$ and $e^{*} \in E^{*}$. Here, we compute $\left(U^{-1}\right)^{*} T\left(e^{*} \otimes \tau_{x}\right)$. Let $f \in \operatorname{lip}(X, E)$ be arbitrary. Then there exists a sequence $\left\{z_{k}\right\}_{k=1}^{\infty}$ in $E \otimes_{\varepsilon} \operatorname{lip}(X)$ such that

$$
\left\|U z_{k}-f\right\|_{\max } \rightarrow 0 \quad(k \rightarrow \infty) .
$$


For each $k=1,2,3, \ldots, z_{k}$ is represented as follows:

$$
z_{k}=\sum_{i=1}^{M_{k}} e_{i}^{(k)} \otimes h_{i}^{(k)}
$$

with some $e_{i}^{(k)} \in E$ and $h_{i}^{(k)} \in \operatorname{lip}(X)$. Since $U$ is an isometric isomorphism, we have

$$
\varepsilon\left(U^{-1} f-z_{k}\right) \rightarrow 0 \quad(k \rightarrow \infty) .
$$

By using equations (1), (3), (4) and (7), we get the following estimate:

$$
\begin{aligned}
& \left|\left(\left(U^{-1}\right)^{*} T\left(e^{*} \otimes \tau_{x}\right)\right)(f)-\left(e^{*} \otimes \tau_{x}\right)(f)\right| \\
& \leq\left|\left(T\left(e^{*} \otimes \tau_{x}\right)\right)\left(U^{-1} f\right)-\left(T\left(e^{*} \otimes \tau_{x}\right)\right)\left(z_{k}\right)\right|+\left|\left(T\left(e^{*} \otimes \tau_{x}\right)\right)\left(z_{k}\right)-\left(e^{*} \otimes \tau_{x}\right)(f)\right| \\
& =\left|\left(T\left(e^{*} \otimes \tau_{x}\right)\right)\left(U^{-1} f-z_{k}\right)\right|+\left|\sum_{i=1}^{M_{k}}\left(e^{*} e_{i}^{(k)}\right) h_{i}^{(k)}(x)-e^{*}(f(x))\right| \\
& =\left|\left(T\left(e^{*} \otimes \tau_{x}\right)\right)\left(U^{-1} f-z_{k}\right)\right|+\left|e^{*}\left(\sum_{i=1}^{M_{k}} h_{i}^{(k)}(x) e_{i}^{(k)}-f(x)\right)\right| \\
& \leq\left\|T\left(e^{*} \otimes \tau_{x}\right)\right\|_{\varepsilon^{*} \varepsilon}\left(U^{-1} f-z_{k}\right)+\left\|e^{*}\right\|_{E^{*}}\left\|\sum_{i=1}^{M_{k}} h_{i}^{(k)}(x) e_{i}^{(k)}-f(x)\right\|_{E} \\
& =\pi\left(e^{*} \otimes \tau_{x}\right) \varepsilon\left(U^{-1} f-z_{k}\right)+\left\|e^{*}\right\|_{E^{*}}\left\|\left(U z_{k}\right)(x)-f(x)\right\|_{E} \\
& \leq\left\|e^{*}\right\|_{E^{*}}\left\|\tau_{x}\right\|_{\operatorname{lip}(X)^{*} \varepsilon}\left(U^{-1} f-z_{k}\right)+\left\|e^{*}\right\|_{E^{*}}\left\|U z_{k}-f\right\|_{\max } .
\end{aligned}
$$

By using (16) and (17), we have

$$
\left(\left(U^{-1}\right)^{*} T\left(e^{*} \otimes \tau_{x}\right)\right)(f)=\left(e^{*} \otimes \tau_{x}\right)(f) .
$$

Now $f$ is arbitrary, so we have

$$
\left(U^{-1}\right)^{*} T\left(e^{*} \otimes \tau_{x}\right)=e^{*} \otimes \tau_{x} .
$$

Therefore, by combining (15) and (18), we have

$$
\left(\left(Q f^{* *}\right)(x)\right)\left(e^{*}\right)=f^{* *}\left(e^{*} \otimes \tau_{x}\right) .
$$

\section{Examples}

In this section, we give several examples using Theorem 1.

Example 4.1. Suppose that $\operatorname{lip}(X)$ separates points uniformly. Let $K$ be a compact Hausdorff space. Let $C(K)$ denote the Banach space of $\mathbb{K}$-valued continuous functions on $K$. Then $C(K)^{*}$ has the approximation property (see e.g. [7, p. 74]). It follows from Theorem 1 that $\operatorname{lip}(X, C(K))^{* *}$ is isometrically isomorphic to $\operatorname{Lip}\left(X, C(K)^{* *}\right)$.

Example 4.2. Suppose that $\operatorname{lip}(X)$ separates points uniformly. Let $(\Omega, \mathfrak{M}, \mu)$ be a $\sigma$-finite measure space and let $p \in[1, \infty]$. Then $L^{p}(\Omega)^{*}$ has the approximation property (see e.g. [6, Theorem 6.16] and [7, pp. 73-74]). It follows from Theorem 1 that $\operatorname{lip}\left(X, L^{p}(\Omega)\right)^{* *}$ 
is isometrically isomorphic to $\operatorname{Lip}\left(X, L^{p}(\Omega)^{* *}\right)$. By noting that $L^{p}(\Omega)$ is reflexive for any $p \in(1, \infty), \operatorname{lip}\left(X, L^{p}(\Omega)\right)^{* *}$ is isometrically isomorphic to $\operatorname{Lip}\left(X, L^{p}(\Omega)\right)$ for any $p \in(1, \infty)$.

Example 4.3. Suppose that $\operatorname{lip}(X)$ separates points uniformly. Let $\mathscr{H}$ be an infinitedimensional Hilbert space. Szankowski showed in $[8]$ that $\mathscr{B}(\mathscr{H})$ does not have the approximation property. Therefore, by [7, Corollary 4.7], $\mathscr{B}(\mathcal{H})^{*}$ does not have the approximation property. On the other hand, if $\operatorname{Lip}(X)$ has the approximation property, then so does $\operatorname{lip}(X)^{*}$ by Theorem A and [7, Corollary 4.7]. It follows from Theorem 1 that $\operatorname{lip}(X, \mathscr{B}(\mathscr{H}))^{* *}$ is isometrically isomorphic to $\operatorname{Lip}\left(X, \mathscr{B}(\mathscr{H})^{* *}\right)$ if $\operatorname{Lip}(X)$ has the approximation property.

Acknowledgement. The author would like to thank the referee for helpful comments to improve the paper.

\section{REFERENCES}

[1] W. G. Bade, P. C. Curtis Jr and H. G. Dales. Amenability and weak amenability for Beurling and Lipschitz algebras. Proc. London Math. Soc. 55 (1987), 359-377.

[2] P. Cembranos and J. Mendoza. Banach Spaces of Vector-Valued Functions (Lecture Notes in Mathematics, 1676). Springer, Berlin, 1997.

[3] L. G. Hanin. Kantorovich-Rubinstein norm and its application in the theory of Lipschitz spaces. Proc. Amer. Math. Soc. 115 (1992), 345-352.

[4] J. A. Johnson. Banach spaces of Lipschitz functions and vector-valued Lipschitz functions. Trans. Amer. Math. Soc. 148 (1970), 147-169.

[5] W. A. Light and E. W. Cheney. Approximation Theory in Tensor Product Spaces (Lecture Notes in Mathematics, 1169). Springer, Berlin, 1985.

[6] W. Rudin. Real and Complex Analysis, 3rd edn. McGraw-Hill, New York, 1987.

[7] R. A. Ryan. Introduction to Tensor Products of Banach Spaces (Springer Monographs in Mathematics). Springer, London, 2002.

[8] A. Szankowski. $\mathscr{B}(\mathscr{H})$ does not have the approximation property. Acta Math. 147 (1981), 89-108.

[9] N. Weaver. Subalgebras of little Lipschitz algebras. Pacific J. Math. 173 (1996), 283-293.

[10] N. Weaver. Lipschitz Algebras. World Scientific, River Edge, NJ, 1999.

Shinnosuke Izumi

Department of Mathematics

Faculty of Science

Shinshu University

Matsumoto 390-8621

Japan

(E-mail: izumi@math.shinshu-u.ac.jp) 